\title{
A hydrologic index based method for determining ecologically acceptable water-level range of Dongting Lake
}

\author{
Jie LIANG, ${ }^{1,2^{*}}$ Xun YU, $, 1,2$ Guangming ZENG,${ }^{1,2^{*}}$ Haipeng WU, ${ }^{1,2}$ Xu LAI, ${ }^{1,2}$ Xiaodong LI, ${ }^{1,2}$ Lu HUANG,,${ }^{1,2}$ Yujie YUAN,,${ }^{1,2}$ \\ Shenglian GUO, ${ }^{3}$ Juan DAI ${ }^{1,2,4}$ \\ ${ }^{1}$ College of Environmental Science and Engineering, Hunan University, 410082 Changsha; ${ }^{2}$ Key Laboratory of Environmental Biology \\ and Pollution Control (Hunan University), Ministry of Education, 410082 Changsha; ${ }^{3}$ School of Water Resource and Hydropower, \\ Wuhan University, 430072 Wuhan; ${ }^{4}$ Changjiang River Scientific Research Institute, No. 23 Huangpu Road, 430001 Wuhan, China \\ *Corresponding authors: liangjie82@163.com; zgming@hnu.edu.cn
}

\begin{abstract}
Water-level fluctuation (WLF) is regarded as a key environmental factor for lake ecosystems. Keeping moderate WLFs approximating to its natural conditions is substantially essential to maintain its biodiversity and integrity. In this study, a hydrological index based method for determining ecologically acceptable water-level range (EAWLR) was illustrated by a case-study of Dongting Lake. This method was proposed based on a consideration of hydrological alterations induced by natural variability and human activity. It was during this process that two hydrological indices, the ratio flow deviation (RFD) and the amended annual proportional flow deviation (AAPFD), played vital roles in change point detection and the determination of EAWLR, respectively. The WLFs are closely related to species richness. The relationship between them follows a hump-backed curve and EAWLR serves as the hump part of the curve. The final results indicated that EAWLRs of Beijinggang, Nanzui and Chenglingji during flood season were 27.78-38.26 m, 25.19-38.45 $\mathrm{m}$ and 24.48-30.96 m, respectively, while those during non-flood season were 18.33-27.79 m, 17.68-29.19 m and 15.59-22.07 m, respectively. The response to the great flood in 1998 and the drought in 2006 of Dongting Lake region verified the rationality of the results. Within the EAWLR, ecosystems can operate normally and have stable community structures to resist external interference.
\end{abstract}

Key words: Water-level fluctuations, ecologically acceptable water-level range, ratio flow deviation, amended annual proportional flow deviation, hydrological alteration.

Received: December 2013. Accepted: July 2014.

\section{INTRODUCTION}

Water-level fluctuation (WLF) is regarded as an important factor for lake ecosystem and it affects the conservation values (Coops et al., 2003). The strong influence of WLFs on lake ecosystem has been well documented in the literature (Coops and Hosper, 2002; Aroviita and Hämäläinen, 2008; Leira and Cantonati, 2008; Punning et al., 2008; Wantzen et al., 2008). It is concluded that WLFs play important roles in water and nutrient balance, transport and relocation of organic materials, physical environment, taxonomic composition, numerical abundance and diversity of macroinvertebrate assemblages and the interaction between aquatic and littoral food webs. These impacts on ecosystems can be connected either directly or indirectly with WLFs and the indirect effects are generally through alteration of habitats (Leira and Cantonati, 2008).

Few lakes have constant water-level regime. WLFs are natural forms of disturbance in lakes, which encompass not only the range, but also the frequency and duration of change (Riis and Hawes, 2002; Leira and Cantonati, 2008; Dolinar et al., 2010; Paillisson and Marion, 2011). It needs to be stressed that WLFs are nec- essary for the survival of many species and weigh heavily in productivity promotion and biodiversity protection (Wantzen et al., 2002, 2008). The relationship between species richness and WLFs follows a hump-backed curve, with niche and species diversity maximal at intermediate degrees of WLFs (Huston, 1994; Riis and Hawes, 2002). In $21 \mathrm{New}$ Zealand lakes, varying in size from 1.4 to $348 \mathrm{~km}^{2}$ and ranging in water depth from a few centimetres to several metres, the species richness rose with increased WLFs up to $1 \mathrm{~m}$ and showed the lowest species richness with WLFs of $2.4 \mathrm{~m}$ (Leira and Cantonati, 2008). However, human activities, including the construction of dams and water abstraction for irrigation and other water uses, have caused hydrological alterations, thus leading to significant changes in WLFs. Natural variability, such as climate change, has further accentuated the alteration trend. In most cases, it is difficult to restore a natural fluctuation because of socioeconomic restrictions. The multiple uses of lakes should be carefully balanced and included in an integrated management scheme of restoring approximately natural WLFs within the permissible limits. In response to the increasingly stringent ecological and economic develop- 
ment crises, managed WLFs have become a potential tool for lake restoration (Coops and Hosper, 2002). Furthermore, ecologically-based fluctuations would be highly desirable (Coops et al., 2003).

Although the role of natural lake WLFs in maintaining species diversity and ecological integrity has been well known to ecologist, there are few quantitative studies on approximate WLFs. In this study, we focused only on the range of the fluctuation. The hydrological alterations induced by natural variability and human activity were analysed by change point detection, and the ecologically acceptable water-level range (EAWLR) was calculated quantitatively by a case-study of Dongting Lake. In the following sections, we first provided information on the methods used in this study. Then the calculated results of Dongting Lake were presented. The subsequent discussion was focused on verifying the rationality of the results. In the final section, we summarized the main conclusions of the paper. The objectives of this study were: i) to propose a method for water resources allocation; and ii) to provide a basis for lake restoration and management.

\section{METHODS}

\section{Study area}

This study was conducted in Dongting Lake, which is the second largest freshwater lake in China. It is an ecologically and economically important source of water for agriculture, industry, domestic use and entertainment. Dongting Lake is located in the middle of the Yangtze River flood plain and the river flows from the northwest into Dongting Lake through three small channels (Songzi, Hudu and Ouchi). Xiangshui River and Zishui River discharge water into the lake from south. Another two tributaries (Yuanshui and Lishui rivers) flow into the lake from west and northwest, respectively (Du et al., 2011; Yao, 2008). All of the water flows back into the Yangtze River through Chenglingji (the sole outlet of Dongting Lake) after regulation and storage (Fig. 1). About 50,000 dams have been constructed in the Yangtze River region. The water storage capacity of major upstream dams totalled $27 \mathrm{~km}^{3}$ in 2000 , and the Three Gorges dam added $39 \mathrm{~km}^{3}$ in 2003. Another 41 $\mathrm{km}^{3}$ will be contributed by the ongoing or planned dams (Xu et al., 2006; Xu and Milliman, 2009; Wu et al., 2013). Due to the constructed dams, silt deposition from connecting rivers in Hunan Province and reclaiming land from lakes, the lake area decreased sharply (An et al., 2007; Vaníčková et al., 2011; Liang et al., 2012). The natural surface area of lake water was $6000 \mathrm{~km}^{2}$ in 1850 , $5400 \mathrm{~km}^{2}\left(10 \%\right.$ reduction) in $1915,4350 \mathrm{~km}^{2}(28 \%$ reduction) in 1950 and $2691 \mathrm{~km}^{2}$ (55\% reduction) in 1987 (Li et al., 2000).
In order to confirm the integrity and continuity of data as well as to simplify analytical processes with typical hydrological stations, monthly average water-level data of three hydrological stations from 1950 to 2005 were used in this study. The first station is Beijinggang hydrological station, one of entrances to Dongting Lake. The second station is Nanzui hydrological station, located in the middle of the lake, and the third is Chenglingji hydrological station, which is the sole outlet of Dongting Lake. In all hydrological stations of Dongting Lake, Chenglingji showed the greatest average intraannual WLFs, while Nanzui showed the smallest fluctuation (Ding and Li, 2011).

\section{Method overview}

For a more theoretically coherent thinking, the flowchart of the proposed method is presented in the following figure (Fig. 2). The method consists of three steps: change point detection, determination of the highest frequency water-level $\left(L_{p m}\right)$ and the determination of EAWLR.

\section{Change point detection}

An observed time series usually exhibit random fluctuation induced by natural variability and human activity. While studying such series, an important question may arise whether stochastic properties of observed time series remain the same over time (Neubauer and Veselý, 2011). Therefore, detection of changes in long time series has vast scientific and practical significance (Kundzewicz et al., 2005). The change is the shift of the series trend slopes or the properties of time series. The time when the shift happened is called the change point. The goal of change point detection is to identify the time moment at which the shift happened (Kawahara and Sugiyama, 2009).

Considering the intra-annual precipitation variability in Dongting Lake region, the water-level series is divided into two parallel parts: the water-level series during flood season (from June to September) and the water-level series during non-flood season (from October to next May). Mann-Kendall trend test and $t$-test are used to detect change points. The change points identified simultaneously by the two detecting methods can be conceived as probable change points (PCPs). The series before the change point is called the reference period and the remaining is called the change period (Kundzewicz and Robson, 2004). Then, the ratio flow deviation (RFD) (Richter et al., 1996), calculated by eq. (1), is introduced into this study to choose a final change point (FCP) from the PCPs for generating a sufficiently long reference period. The RFD represents the deviation of water-level at PCP from other water-levels in time series. A larger RFD value indicates a greater deviation magnitude, and this will lead 
to more significant changes. Therefore, the PCP with the largest RFD value is identified as the FCP.

$$
\begin{array}{ll}
R F D_{k}=\sum_{j=1}^{n}\left[\frac{1}{12} \sum_{i=1}^{12} r_{i j}-1\right] \\
r_{i j}=\frac{H_{k}}{h_{i j}} & H_{k} \geq h_{i j} \\
r_{i j}=\frac{h_{i j}}{H_{k}} & h_{i j} \geq H_{k}
\end{array}
$$

where $h_{i j}$ is the water-level of month $i$ in the year $j, H_{k}$ is the water-level at PCP $k$, and $n$ represents the number of years.

\section{Determination of the highest frequency water-level}

Over the long evolutionary process, ecosystems have evolved with adaptations to high frequency water-level, which is generally believed to be close to its natural regime and fundamentally important to sustainable development of ecosystems (Zhong et al., 2005). For hydrologic frequency analysis, it can proceed by fitting hydrological probability distributions to water-level data. More explicitly, the procedure is composed of the following steps: i) fit hydrological probability distributions to the reference period; ii) select the optimal distribution from four candidate distributions based on Kolmogorov-

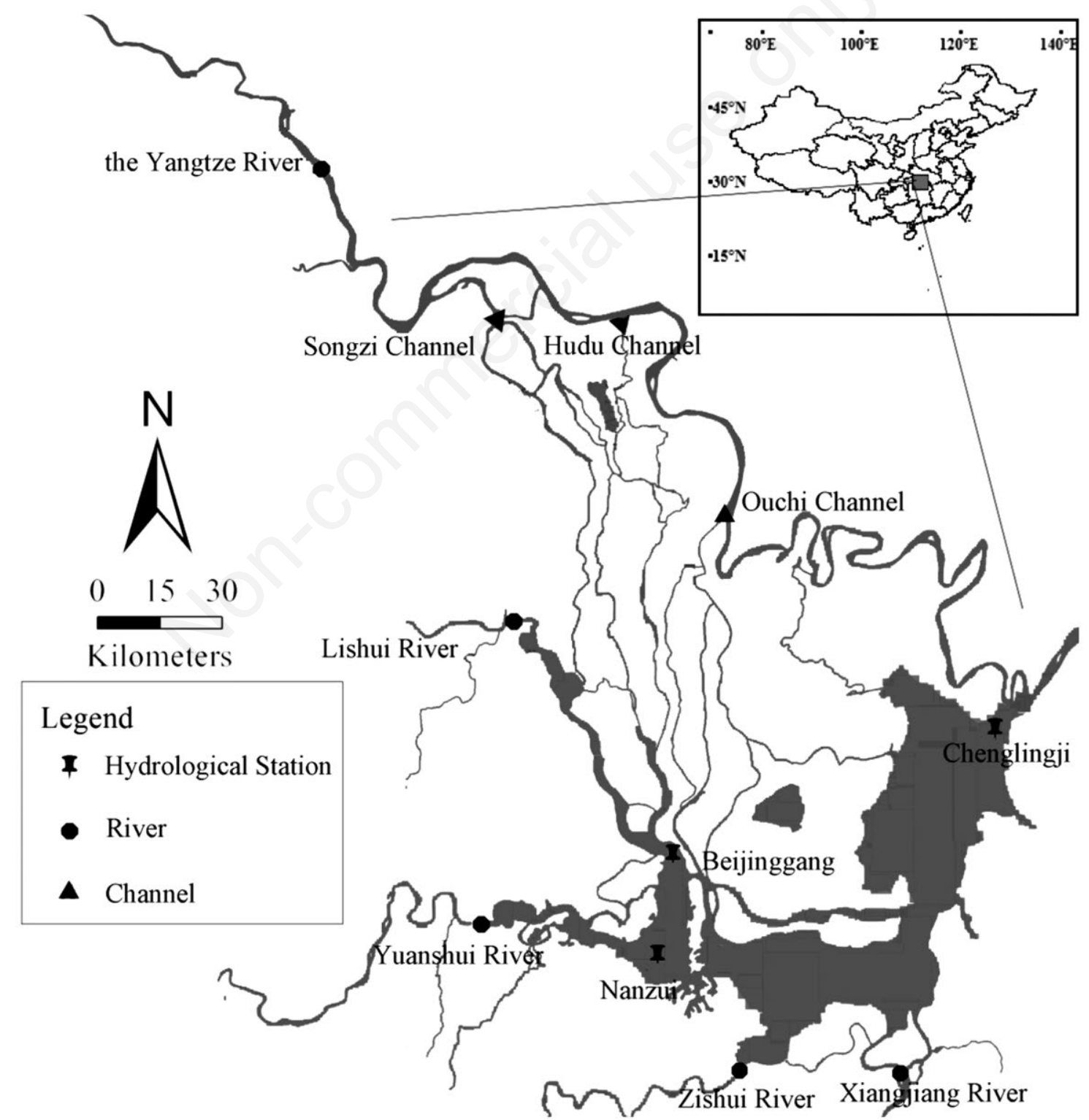

Fig. 1. The river-lake system in the Dongting Lake region. 


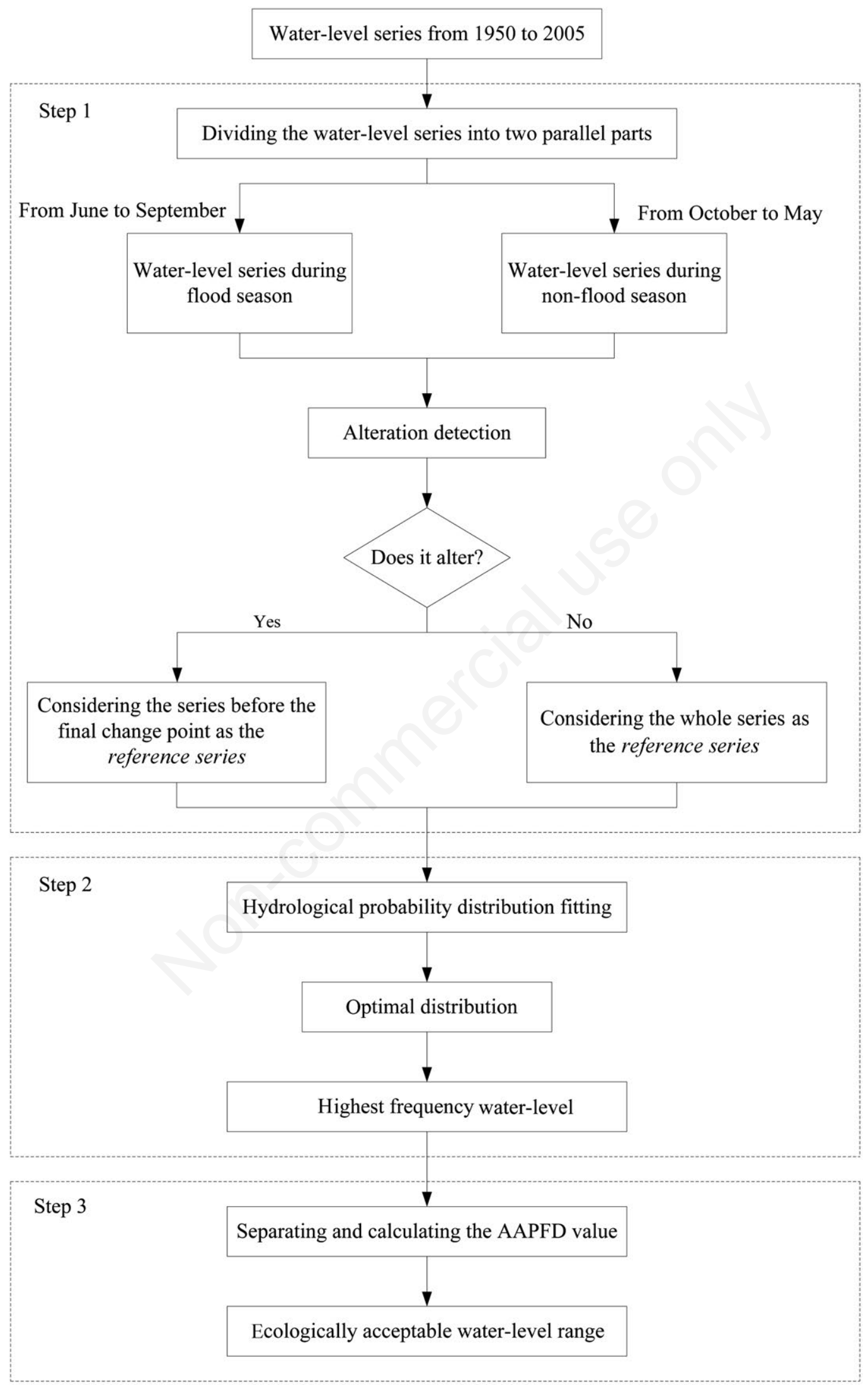

Fig. 2. The flowchart of the proposed method. 
Smirnov (K-S) method; iii) determine the highest frequency water-level $\left(L_{p m}\right)$.

Four extensively used hydrological probability distributions have been employed to fit to the reference period: Pearson type-III (P-III), generalized extreme value (GEV), generalized Pareto (GP) and log-normal (LN) distributions (Hamed, 2009; Laio et al., 2009). K-S method is a widely accepted approach for evaluating the goodness of fit of alternative distributions to observations. The $\mathrm{P}$ value indicates the degree to which the statistical character of the data record matches those of the candidate distributions. Among the four candidates, the one with the largest $\mathrm{P}$ value is recommended as the optimal probability distribution. $L_{p_{m}}$ can be calculated using the identified optimal distribution.

\section{Determination of ecologically acceptable water-level range}

The amended annual proportional flow deviation (AAPFD) was originally developed by Gehrke et al. (1995). It quantifies the deviation degree of the hydrological pattern by calculating monthly water-level deviation from the annual average water-level. It has a minimum of zero (no change to water-level) but no upper limit. Larger AAPFD value means a stronger influence of natural or human activities on ecosystems, which demonstrates a poorer health status of ecosystems (Marchant and Hehir, 2002; Growns, 2008; Biemans et al., 2011). It is defined as:

$$
A A P F D=\frac{1}{n} \sum_{j=1}^{n}\left[\sum_{i=1}^{12}\left(\frac{H-h_{i j}}{\bar{h}_{j}}\right)^{2}\right]^{\frac{1}{2}}
$$

where $h_{i j}$ is the water-level of month $i$ in the year $j, H$ is the ecologically acceptable water-level, $n$ is the number of the years, and $\bar{h}_{j}$ his the average water-level in the year $j$.

The relationship between AAPFD and ecosystem health score was established by Chen et al. (2012). The ecosystem in completely natural state gets the highest score of 10 , and that suffers from severe interference gets the lowest score of 0.6 is the critical value of ecosystem health score. The conditions of the ecosystem are acceptable when the ecosystem health score is above 6. According to the relationship between AAPFD and ecosystem health score (Tab. 1), the maximally acceptable value of
AAPFD is 1 . Usually, $L_{p_{m}}$ deviates slightly from the average water-level and its AAPFD value is much less than 1. Therefore, two extreme water-levels in both sides of $L_{p_{m}}$ can be found, whose AAPFD values exactly equal to 1 . The water-level range between the two extreme waterlevels is defined as the EAWLR.

\section{RESULTS}

\section{Change point detection}

The water-level changes were detected by MannKendall trend test at the significance level of 5\% (Fig. 3). It was found that the UF values of Beijinggang from 1954 to 1957 were positive during flood season, which meant that the time series had an increasing trend over this period. Its Mann-Kendall trends during non-flood season presented a similar pattern. During flood season, the UF values of Nanzui were positive from 1955 to 1958, and then became negative. Over the period of 1985-1998, it fluctuated around 0 . However, during non-flood season, the time series showed a downward trend except in the year 1952 and 1953. As for Chenglingji, two periods with upward trend were identified both during flood season and non-flood season. One was in the year 1955, the other was from 1980 to 2005 for flood season and from 1975 to 2005 for non-flood season. Moreover, affected by the Yangtze River, the waterlevel of Chenglingii showed comparatively greater fluctuation than the other two hydrological stations. When the time series were detected by Mann-Kendall trend test and $t$ test, there were no significant changes of Chenglingji during flood season. In other cases, the change points identified by Mann-Kendall trend test differed from those identified by $t$-test (Tab. 2). The integrated results of two detecting methods indicated that only two FCPs had been identified, one was Dec. in 1958 at Beijinggang, the other was May in 1966 at Nanzui (Tab. 3).

\section{Determination of $\mathbf{L}_{p m}$}

In this study, the K-S method was used to determine the best fitting model from the four candidate hydrological probability distributions. The goodness of fit indices at the significance of $5 \%$ were calculated (Tab. 4). The one with the highest $\mathrm{P}$ value is perceived as the optimal distribution, except for the Generalized Pareto distribution

Tab. 1. The relationship between the value of the amended annual proportional flow deviation and the ecosystem health score.

\begin{tabular}{lccccc}
\hline AAPFD & Ecosystem health score & AAPFD & Ecosystem health score & AAPFD & Ecosystem health score \\
\hline $0-0.1$ & 10 & $0.1-0.2$ & 9 & $0.2-0.3$ & 8 \\
$0.3-0.5$ & 7 & $0.5-1.0$ & 6 & $1.0-1.5$ & 5 \\
$1.5-2$ & 4 & $2.0-3.0$ & 3 & $3.0-4.0$ & 2 \\
$4.0-5.0$ & 1 & $>5$ & 0 & & \\
\hline
\end{tabular}

$A A P F D$, amended annual proportional flow deviation. 
due to its monotonicity. It can be seen that the GEV distribution ranked consistently best, excluding the case of Chenglingji hydrological station during flood season. In this case, it can be well approximated by a LN distribution, with the $\mathrm{P}$ value reaching 0.86167 . The correspon$\operatorname{ding} L_{p_{m}}$ was also computed (Tab. 4).

\section{Ecologically acceptable water-level range}

The EAWLRs of the three hydrological stations were calculated, which provided a basis for water-level control of Dongting Lake (Tab. 5). As can be seen, the EAWLR of Chenglingji hydrological station was restricted in the narrowest range, while Beijinggang hydrological station was revealed to have the widest range. Within this range, the ecosystems possessed adequately strong resilience and resistance to external disturbances (Adger, 2000).

\section{DISCUSSION}

The environment flow methodologies could be differentiated into hydrological, hydraulic rating, habitat simulation and holistic methodologies, with a further two categories representing combination-type and other approaches (Tharme, 2003). The lake morphology analytic approach, one of hydrological methodologies, has been widely used to determine a water-level appropriate for lake ecosystems. The relationship between change rate of lake surface area and water-level can be established based on curve fitting. It assumes that the water-level at flex point of the curve would provide satisfactory conditions for lake ecosystems (Xu et al., 2004). According to the relationship between the change rate of Dongting Lake surface area and the water-level at Chenglingji (Kameyama et al., 2004), the water-levels appropriate for lake ecosystems calculated by lake morphology analytic approach were $29.05 \mathrm{~m}$ during flood season and $19.34 \mathrm{~m}$ during non-flood season. They were both within EAWLRs. Compared with lake morphology analytic approach, the strengths of the method proposed in this paper lie in the consideration of hydrological alterations and the resistant and resilient abilities of ecosystems. The great flood in 1998, lasted from June to August, was a catastrophic disaster. It caused the death of 4150 people and $\$ 30$ billion worth of economic damage (Hayashi et al., 2008; Gao et al., 2007). In 1998, the average water-levels of Beijinggang, Nanzui, and Chenglingji in June, July and August exceeded the upper limit of EAWLR, especially of Chenglingji. The average water-levels in the three

Tab. 2. The change points identified by Mann-Kendall trend test and $t$-test.

\begin{tabular}{|c|c|c|c|}
\hline $\begin{array}{l}\text { Hydrological } \\
\text { station }\end{array}$ & Periods & Mann-Kendall trend test & Change points \\
\hline \multirow[t]{2}{*}{ Beijinggang } & Flood season & Flood season in 1956 and 1957; Jun. 1958 & Sep. 1958; flood season in 1959-1977 \\
\hline & Non-flood season & $\begin{array}{l}\text { May 1951; Oct. 1951; } \\
\text { non-flood season in 1955-1958; Jan. and Feb. } 1959\end{array}$ & $\begin{array}{l}\text { Mar.-May 1951; Oct.-Dec. } 1952 \text { and 1955; } \\
\text { non-flood season in 1956-1962 }\end{array}$ \\
\hline \multirow[t]{2}{*}{ Nanzui } & Flood season & $\begin{array}{l}\text { Aug. and Sep. 1953; } \\
\text { flood season in 1954-1957; } \\
\text { flood season in } 2000 \text { and 2001; Jun. } 2002\end{array}$ & Jul.-Sep. 1960; flood season in 1972 and 1973 \\
\hline & Non-flood season & $\begin{array}{l}\text { Non-flood season in } 1952 \text { and } 1953 \text {; } \\
\text { Jan.-Apr. 1954; non-flood season in } 1965 \text { and } 1966\end{array}$ & Sep.-Nov. 1952; Dec. 1965-May 1966 \\
\hline Chenglingji & $\begin{array}{l}\text { Flood season } \\
\text { Non-flood season }\end{array}$ & $\begin{array}{l}\text { No change points } \\
\text { No change points }\end{array}$ & $\begin{array}{l}\text { No change points } \\
\text { Non-flood season in } 1956 \text { and 1959; Feb.-May } 1982\end{array}$ \\
\hline
\end{tabular}

Tab. 3. The final change points jointly determined by Mann-Kendall trend test and $t$-test.

\begin{tabular}{|c|c|c|c|c|}
\hline Hydrological station & Periods & FCP & RFD value & Reference period \\
\hline \multirow[t]{2}{*}{ Beijinggang } & Flood season & No alteration & - & Jan. 1950-Dec. 2005 \\
\hline & Non-flood season & Dec. 1958 & 1.2055 & Jan. 1950-Nov. 1958 \\
\hline \multirow[t]{2}{*}{ Nanzui } & Flood season & No alteration & - & Jan. 1950-Dec. 2005 \\
\hline & Non-flood season & May 1966 & 1.4556 & Jan. 1950-Apr. 1966 \\
\hline \multirow[t]{2}{*}{ Chenglingji } & Flood season & No alteration & - & Jan. 1950-Dec. 2005 \\
\hline & Non-flood season & No alteration & - & Jan. 1950-Dec. 2005 \\
\hline
\end{tabular}

FCP, final change point; RFD, ratio flow deviation. 

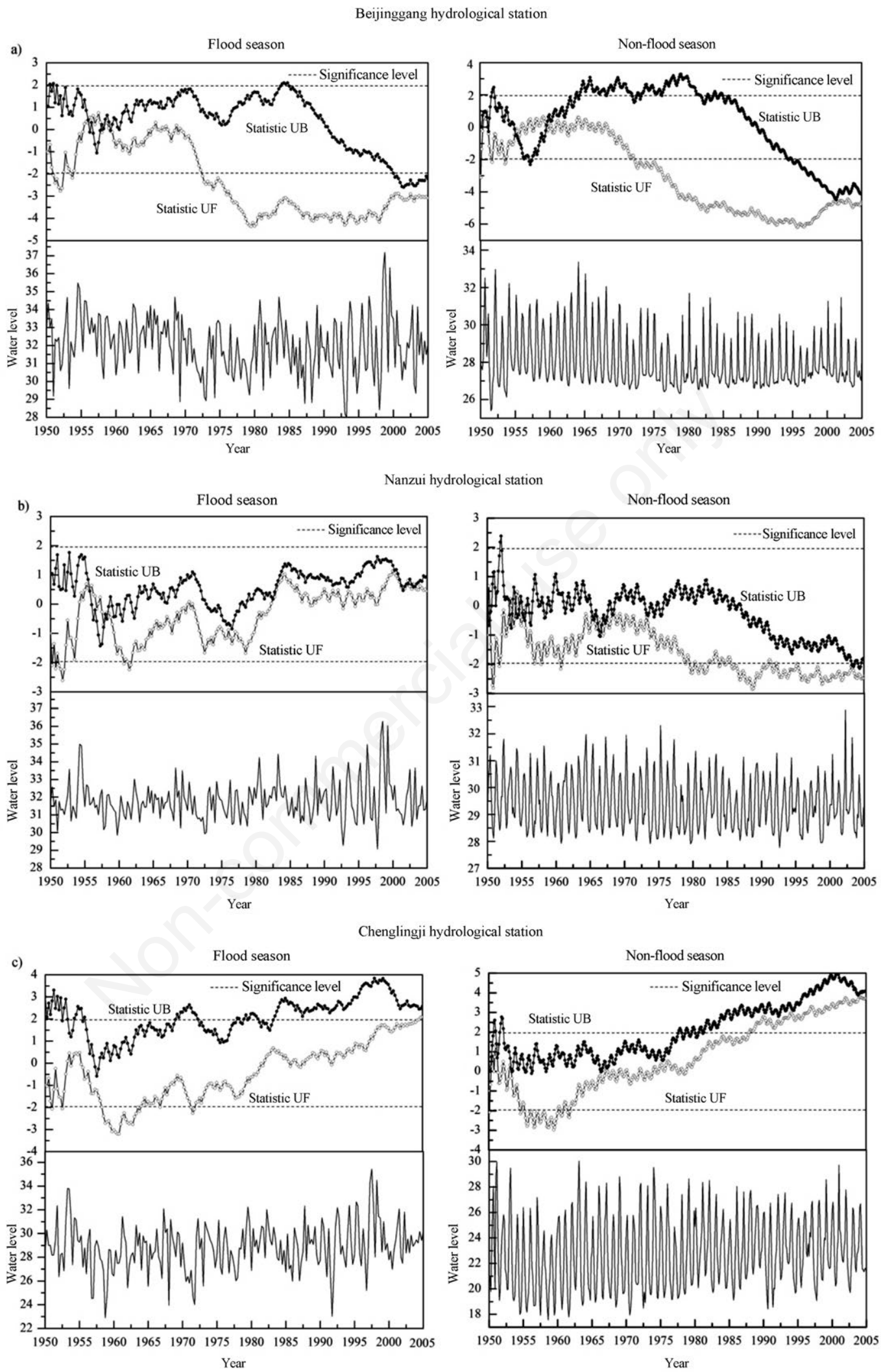

Fig. 3. Change point detection by Mann-Kendall trend test at the significance level of 5\%. UF and UB are the test statistics. The positive UF indicates that the time series has an increasing trend at that time, and the negative one indicates the opposite trend. If the UF and UB curve intersect between the significance values, the time series has a sudden change at that time. 
months of Chenglingii respectively were $33.53 \mathrm{~m}, 35.46$ $\mathrm{m}$, and $35.92 \mathrm{~m}$, which were higher than $30.96 \mathrm{~m}$ (the upper limit of EAWLR). Excessively high water-level would change soils from oxic to anoxic. The species that can not adapt to it would produce toxic ethanol under anoxic conditions, which not only retards their own growth, but also leads to the damage to other species.

Under the influence of extremely high temperatures, low annual rainfall and the impoundment of the Three Gorges Dam from $135 \mathrm{~m}$ to $156 \mathrm{~m}$, the flood season in 2006 has seen a severe drought in the Yangtze River basin (Dai et al., 2008). During the whole flood season in 2006, the average water-levels of Beijinggang, Nanzui, and Chenglingji were lower than the lower limit of EAWLR, especially of Beijinggang. The average water-levels of Beijinggang from June to September were $28.61 \mathrm{~m}, 28.68$ $\mathrm{m}, 27.82 \mathrm{~m}$ and $25.06 \mathrm{~m}$, respectively. Each of them was lower than $28.78 \mathrm{~m}$ (the lower limit of EAWLR). Extremely low water-level would cause much damage to ecosystems. It has been identified as the major potential causes of reed decline (Dienst et al., 2004). Loss of reed leads to reduced survival fishes, which further hindered the processes of internal nutrient cycling (Zohary and Ostrovsky, 2011). Reduction of marginal zones around the lake resulted from low water-level is another serious dam- age to aquatic species (Cui et al., 2010). Additionally, exposure of new substrate during periods of extremely low water-levels may facilitate the expansion of emergent plants, which leads to the massive occupation of ecological space (Leira and Cantonati, 2008). Rhodes and Wiley (1993) have reported that the declining water-levels may cause contaminated sediments to be re-suspended and this would represent a potentially long-term environmental remediation problem.

The lower and upper limits are given by EAWLR. Below the lower limit or beyond the upper limit, the ecosystems often move to a poor health state, and even show a breakdown of the ecological restoration functions, which may be difficult to restore. By eliminating woody plants, moderate water-levels increase marsh area and marsh diversity (Keddy and Reznicek, 1986). This is consistent with Riis and Hawes (2002), who hold the opinion that the increased species diversity caused by moderately increased water-level might due to the increased habitat area. An increased area can comprise more niches, and cover a larger range of environmental gradients. Abundant species with different environmental tolerances promote species coexistence and enhance the resistant and resilient abilities of communities to disturbances (Huston, 1994).

Tab. 4. The goodness of fit indices at the significance of 5\%.

\begin{tabular}{|c|c|c|c|c|c|c|c|}
\hline Hydrological station & Periods & Statistic & P-III & GEV & GP & LN & $\mathrm{L}_{p m}$ \\
\hline \multirow[t]{4}{*}{ Beijinggang } & Flood season & $\mathrm{p}$ & 0.53318 & 0.44485 & 0.69851 & $\underline{0.83622}$ & $33.03 \mathrm{~m}$ \\
\hline & & $\mathrm{D}$ & 0.14445 & 0.15494 & 0.12616 & $\underline{\underline{0.11008}}$ & \\
\hline & Non-flood season & $\mathrm{p}$ & 0.38570 & 0.44381 & 0.40017 & $\underline{0.40724}$ & $27.79 \mathrm{~m}$ \\
\hline & & $\mathrm{D}$ & 0.10978 & 0.10474 & 0.10848 & $\underline{0.10786}$ & \\
\hline \multirow[t]{4}{*}{ Nanzui } & Flood season & $\mathrm{p}$ & 0.72202 & 0.17088 & 0.68093 & $\underline{0.83946}$ & $31.32 \mathrm{~m}$ \\
\hline & & $\mathrm{D}$ & 0.04562 & 0.07334 & 0.04726 & $\underline{\underline{0.04058}}$ & \\
\hline & Non-flood season & $\mathrm{p}$ & 0.16009 & 0.98497 & 0.14356 & $\underline{0.31080}$ & $29.19 \mathrm{~m}$ \\
\hline & & $\mathrm{D}$ & 0.07673 & 0.03081 & 0.07839 & $\overline{0.06573}$ & \\
\hline \multirow[t]{4}{*}{ Chenglingji } & Flood season & $\mathrm{p}$ & 0.63286 & 0.14298 & $\underline{0.86167}$ & 0.77144 & $28.76 \mathrm{~m}$ \\
\hline & & $\mathrm{D}$ & 0.04960 & 0.07666 & $\underline{0.03986}$ & 0.04398 & \\
\hline & Non-flood season & $\mathrm{p}$ & 0.11114 & 0.76383 & 0.10167 & $\underline{0.18096}$ & $22.07 \mathrm{~m}$ \\
\hline & & $\mathrm{D}$ & 0.05718 & 0.03161 & 0.05806 & $\underline{0.05210}$ & \\
\hline
\end{tabular}

P-III, Pearson type-III distribution; GEV, generalized extreme value distribution; GP, generalized Pareto distribution; LN, Log-normal distribution.

Tab. 5. The ecologically acceptable water-level ranges of Dongting Lake.

\begin{tabular}{|c|c|c|c|c|c|c|}
\hline \multirow[t]{2}{*}{ Hydrological station } & \multicolumn{3}{|c|}{ Flood season } & \multicolumn{3}{|c|}{ Non-flood season } \\
\hline & Lower limit & $\mathbf{L}_{p m}$ & Upper limit & Lower limit & $\mathrm{L}_{p m}$ & Upper limi \\
\hline Beijinggang & $28.78 \mathrm{~m}$ & $33.03 \mathrm{~m}$ & $38.26 \mathrm{~m}$ & $18.33 \mathrm{~m}$ & $22.56 \mathrm{~m}$ & $27.79 \mathrm{~m}$ \\
\hline$\overline{\text { Nanzui }}$ & $25.19 \mathrm{~m}$ & $31.32 \mathrm{~m}$ & $38.45 \mathrm{~m}$ & $17.68 \mathrm{~m}$ & $22.09 \mathrm{~m}$ & $29.19 \mathrm{~m}$ \\
\hline Chenglingji & $24.48 \mathrm{~m}$ & $28.76 \mathrm{~m}$ & $30.96 \mathrm{~m}$ & $15.59 \mathrm{~m}$ & $18.83 \mathrm{~m}$ & $22.07 \mathrm{~m}$ \\
\hline
\end{tabular}




\section{CONCLUSIONS}

Few lakes have a constant water-level regime and WLFs weigh heavily in lake ecosystems. They are connected with ecological responses directly or indirectly. Either excessively high or low water-levels would impose adverse impacts on ecosystems. A moderate water-level range, EAWLR, was proposed based on a consideration of hydrological alterations in this study. The relationship between species richness and WLFs follows a humpbacked curve and EAWLR serves as the hump part of the curve. Compared with lake morphology analytic approach, the strengths of the method proposed in this paper lies in the consideration of hydrological alterations and the resistant and resilient abilities of ecosystems.

\section{ACKNOWLEDGMENTS}

This project was financially supported by the National Natural Science Foundation of China (51009063, 51039001, 51479072 and 51109016) and the Scientific Research Project for the Three Gorges' Environmental Protection (SX 2010-026).

\section{REFERENCES}

Adger WN, 2000. Social and ecological resilience: are they related? Prog. Hum. Geog. 24:347-364.

An S, Li H, Guan B, Zhou C, Wang Z, Deng Z, Zhi Y, Liu Y, Xu C, Fang S, Jiang J, Li H, 2007. China's natural wetlands: past problems, current status, and future challenges. J. Human Environ. 36:335-342.

Aroviita J, Hämäläinen H, 2008. The impact of water-level regulation on littoral macroinvertebrate assemblages in boreal lakes. Hydrobiologia 613:45-56.

Biemans H, Haddeland I, Kabat P, Ludwig F, Hutjes RWA, Heinke J, von Bloh W, Gerten D, 2011. Impact of reservoirs on river discharge and irrigation water supply during the $20^{\text {th }}$ century. Water Resour. Res. 47:W03509.

Chen H, Yang L, Yang ZF, Yu SW, 2012. Sustainable reservoir operations to balance upstream human needs and downstream lake ecosystem targets. Procedia Environ. Sci. 13:1444-1457.

Coops H, Beklioglu M, Crisman TL, 2003. The role of waterlevel fluctuations in shallow lake ecosystems-workshop conclusions. Hydrobiologia 506-509:23-27.

Coops H, Hosper SH, 2002. Water-level management as a tool for the restoration of shallow lakes in the Netherlands. Lake Reserv. Manage. 18:293-298.

Cui B, Li X, Zhang K, 2010. Classification of hydrological conditions to assess water allocation schemes for Lake Baiyangdian in North China. J. Hydrol. 385:247-256.

Dai Z, Du J, Li J, Li W, Chen, J 2008. Runoff characteristics of the Changjiang River during 2006: Effect of extreme drought and the impounding of the Three Gorges Dam. Geophys. Res. Lett. 35:L07406.

Dienst M, Schmieder K, Ostendorp W, 2004. Effects of water level variations on the dynamics of the reed belts of Lake Constance. Limnologica 34:29-36.

Ding XW, Li XF, 2011. Monitoring of the water-area variations of Lake Dongting in China with ENVISAT ASAR images. Int. J. Appl. Earth Obs. 13: 894-901.

Dolinar N, Rudolf M, Šraj N, Gaberščik A, 2010. Environmental changes affect ecosystem services of the intermittent Lake Cerknica. Ecol. Complex. 7:403-409.

Du Y, Xue H, Wu S, Ling F, Xiao F, Wei X, 2011. Lake area changes in the middle Yangtze region of China over the $20^{\text {th }}$ century. J. Environ. Manage. 92:248-255.

Gao J, Nickum JE, Pan Y, 2007. An assessment of flood hazard vulnerability in the Dongting Lake Region of China. Lakes Reserv. Res. Manage. 12:27-34.

Gehrke PC, Brown P, Schiller CB, Moffatt DB, Bruce AM, 1995. River regulation and fish communities in the MurrayDarling river system, Australia. Regul. River. 15:181-198.

Growns I, 2008. The influence of changes to river hydrology on freshwater fish in regulated rivers of the Murray-Darling basin. Hydrobiologia 596:203-211.

Hamed KH, 2009. Exact distribution of the Mann-Kendall trend test statistic for persistent data. J. Hydrol. 365:86-94.

Hayashi S, Murakami S, Xu K, Watanabe M, 2008. Effect of the Three Gorges Dam Project on flood control in the Dongting Lake area, China, in a 1998-type flood. J. Hydro-Environ. Res. 2:148-163.

Huston MA, 1994. Biological diversity: the coexistence of species in changing landscapes. Cambridge University Press: 681 pp.

Kameyama S, Zhang J, Wang Q, Xu K, Katoh T, Watanabe M, 2004. [An approach to estimate the water level and volume of Dongting Lake using Terra/MODIS data].[Article in Chinese]. Acta Geogr. Sinica 59:88-94.

Kawahara Y, Sugiyama M, 2009. Change-point detection in time-series data by direct density-ratio estimation, p. 389400. Proceedings of 2009 SIAM international conference on data mining, Sparks, NE, USA.

Keddy PA, Reznicek AA, 1986. Great lakes vegetation dynamics: the role of fluctuating water levels and buried seeds. J. Great Lakes Res. 12: 25-36.

Kundzewicz ZW, Graczyk D, Maurer T, Pińskwar I, Radziejewski M, Svensson C, Szwed M, 2005. Trend detection in river flow series: 1. annual maximum flow. Hydrol. Sci. J. 50:779-809.

Kundzewicz ZW, Robson A, 2004. Change detection in hydrological records-review of the methodology/Revue méthodologique de la détection de changements dans les chroniques hydrologiques. Hydrol. Sci. J. 49:7-19.

Laio F, Baldassarre GD, Montanari A, 2009. Model selection techniques for the frequency analysis of hydrological extremes. Water Resour. Res. 45:W07416.

Leira M, Cantonati M, 2008. Effects of water-level fluctuations on lakes: an annotated bibliography. Hydrobiologia 613: 171-184.

Li YS, Sleigh AC, Ross AGP, Li Y, Williams GM, Tanner M, McManus DP, 2000. Epidemiology of Schistosoma japonicum in China: morbidity and strategies for control in the Dongting Lake region. Int. J. Parasitol. 30:273-281.

Liang J, Cai Q, Guo SL, Xie GX, Li XD, Huang L, Zeng GM, Long Y, Wu HP, 2012. [MODIS-based analysis of wetland area responses to hydrological processes in the Dongting Lake].[Article in Chinese]. Acta Ecol. Sinica 32:6628-6635.

Marchant R, Hehir G, 2002. The use of AUSRIVAS predictive models to assess the response of lotic macroinvertebrates to dams in south-east Australia. Freshwater Biol. 47:1033-1050. 
Neubauer J, Veselý V, 2011. Change point detection by sparse parameter estimation. Informatica 22:149-164.

Paillisson JM, Marion L, 2011. Can small water level fluctuations affect the biomass of Nymphaea alba in large lakes? Aquat. Bot. 84:259-266.

Punning J, Kapanen G, Hang T, Davydova N, Kangur M, 2008. Changes in the water level of Lake Peipsi and their reflection in a sediment core. Hydrobiologia 599:97-104.

Rhodes SL, Wiley KB, 1993. Great Lakes toxic sediments and climate change. Implications for environmental remediation. Global Environ. Chang. 3:292-305.

Richter BD, Baumgartner JV, Powell J, Braun DP, 1996. A method for assessing hydrologic alteration within ecosystems. Conserv. Biol. 10:1163-1174.

Riis T, Hawes I, 2002. Relationships between water level fluctuations and vegetation diversity in shallow water of New Zealand lakes. Aquat. Bot. 74:133-148.

Tharme RE, 2003. A global perspective on environmental flow assessment: emerging trends in the development and application of environmental flow methodologies for rivers. River Res. Applic. 19:397-441.

Vaníčková I, Seda J, Macháček J, Petrusek A, 2011. Effects of extreme floods on the Daphnia ephippial egg bank in a long narrow reservoir. J. Limnol. 70:368-377.

Wantzen KM, de Arruda Machado F, Voss M, Boriss H, Junk WJ, 2002. Seasonal isotopic shifts in fish of the Pantanal wetland, Brazil. Aquat. Sci. 64:239-251.
Wantzen KM, Rothhaupt K-Q, Mörtl M, CantonatiTóth LG, Fischer P, 2008. Ecological effects of water-level fluctuations in lakes: an urgent issue. Hydrobiologia 613:1-4.

Wu H, Zeng G, Liang, J, Zhang J, Cai Q, Huang L, Li X, Zhu H, $\mathrm{Hu}$ C, Shen S, 2013. Changes of soil microbial biomass and bacterial community structure in Dongting Lake: impacts of 50,000 dams of Yangtze River. Ecol. Eng. 57:72-78.

Xu KH, Milliman JD, 2009. Seasonal variations of sediment discharge from the Yangtze River before and after impoundment of the Three Gorges Dam. Geomorphology 104:276-283.

Xu KH, Milliman JD, Yang ZS, Wang HJ, 2006. Yangtze sediment decline partly from Three Gorges Dam. EOS 87:185-190.

Xu ZX, Chen MJ, Dong ZC, 2004. Researches on the calculation methods of the lowest ecological water level of lake. [Article in Chinese]. Acta Ecol. Sinica 24:2324-2328.

Yao Z, 2008. Comparison between BCR sequential extraction and geo-accumulation method to evaluate metal mobility in sediments of Dongting Lake, Central China. Chin. J. Oceanol. Limnol. 26:14-22.

Zhong P, Yang ZF, Cui BS, Liu JL, 2005. [Studies on water resource requirement for eco-environment of the Baiyangdian wetland].[Article in Chinese]. Acta Scientiae Cirumstantiae 25:1119-1126.

Zohary T, Ostrovsky I, 2011. Ecological impacts of excessive water level fluctuations in stratified freshwater lakes. Inland Waters 1:47-59. 